\title{
EL «ESPÍRITU DE LO GROTESCO» EN EL TEATRO DE ANGÉLICA LIDDELL
}

\section{THE «SPIRIT OF THE GROTESQUE» IN ANGÉLICA LIDDELL DRAMATIC PLAYS}

\author{
Emmanuelle GARNIER \\ Université de Toulouse (Francia) \\ LLA Créatis / Roswita \\ garnier@univ-tlse2.fr
}

Resumen: El teatro de la dramaturga, directora y actriz Angélica Liddell, por su estética neobarroca hecha de contrastes, paradojas y fusión de géneros (aproximación de lo grave y lo ligero, lo sagrado y lo profano, del amor y del asco, de lo festivo y lo trágico...), por las figuras grotescas que convoca, específicamente en lo que al tratamiento del espacio, del cuerpo y del lenguaje se refiere, recoge el espíritu de lo grotesco para construir el camino de la necesaria subversión artística.

Abstract: The theatrical aesthetics of the playwright, stage director and actress Angélica Liddell are made of contrasts, paradoxes and fusion of genders. They mix the serious and the lightweight, the sacred and the profane, love and hate, festive and tragic. Because of the grotesque figures that her theater calls up, specifically regarding to the way it treats space, body and language, it takes up the spirit of the grotesque to build the way to necessary artistic subversion. 
Palabras clave: Angélica Liddell. Estética neobarroca. Figuras grotescas. Violencia poética. Subversión.

Key Words: Angélica Liddell. Baroque Aesthetics. Grotesque Figures. Poetical Violence. Subversion.

Un estudio sobre lo grotesco en las dramaturgas españolas contemporáneas no podía dejar de interrogar el trabajo artístico de Angélica Liddell. Este acercamiento es tanto más interesante cuanto que la artista desarrolla un proyecto dramatúrgico y escénico frente al que las veleidades taxonomistas de los investigadores fracasan y los lleva con frecuencia a clasificar y a integrar a la creadora en la categoría de «bicho raro». De tal forma que, a la pregunta planteada ex abrupto: «ies grotesco el teatro de Angélica Liddell?», contestamos naturalmente que no, para inmediatamente matizar la respuesta, conscientes de que la pregunta es reversible, y de que nos remite directamente a otra, mucho más compleja: «¿Qué es lo grotesco?».

Una rápida mirada de conjunto a comentarios y discursos críticos aparecidos en Internet relativos a la producción de Angélica Liddell muestra que se recurre a veces a este concepto para hablar de alguno de sus espectáculos desde una perspectiva estética, temática o hermenéutica. Una frase en particular se repite en varios escritos de periodistas, más o menos adaptada a la sintaxis circunstancial: «Las obras de Angélica Liddell transitan la oscuridad, lo grotesco y un sorprendente lirismo con el que ilumina el lado más oscuro del ser humano» ${ }^{1}$. Observaremos que esta hermosa y astuta fórmula rodea de forma elegante la cuestión de la factura, del tratamiento o del proceso grotesco puesto en práctica o no en el teatro del que habla, al considerar lo grotesco como un

\footnotetext{
${ }^{1}$ Sin saber precisamente si este texto fue sacado de un dossier de prensa a disposición de los periodistas o si se trata de una cita de uno de ellos, me contentaré con mencionar una cronología (sin duda incompleta). Itzíar de Francisco escribía en El Mundo: «Con Angélica Liddell no hay confusión: sus obras transitan la oscuridad, lo grotesco y un sorprendente lirismo con el que ilumina el lado más oculto del ser humano» (01/04/2004). El artículo se reproduce en el Boletín del Centro Latinoamericano de Creación e Investigación Teatral (CELCIT), 3 de abril de 2004 (235), URL: http://mx.dir.groups.yahoo.com/group/ redactuar/message/915? l=1, consultado el 29 de julio de 2011. El Teatro El Musical (TEM) de El Cabanyal / Canyamelar - València, escribía en junio de 2008, para presentar la obra Y los peces salieron a combatir contra los hombres: «Las obras de Lidell [sic] transitan la oscuridad, lo grotesco y poseen un sorprendente lirismo con el que ilumina el lado más oculto del ser humano», URL: http://www.teatre-elmusical. com/ficha2valencia.php?ide $=78$, consultado el 29 de julio de 2011. Dos años más tarde, la misma fórmula reaparecía en las columnas numéricas del Diario Crítico de la Comunitat Valenciana del 2 de diciembre de 2010, acerca de El año de Ricardo: «Sus obras transitan los confines de la oscuridad, lo brutal y lo grotesco que contrasta con un sorprendente lirismo con el que ilumina el lado más oculto del ser humano», artículo en línea, URL: http://www.diariocriticocv.com/noticias/el/teatro/de/los/manantiales/ estrena/en /primicia/el/ano/de/ricardo/not185576.html, consultado el 29 de julio de 2011.
} 
territorio que los espectáculos recorrerían. Remitiéndonos de esta manera a la pregunta inicial: «¿Qué es lo grotesco?». Por otra parte, en su presentación para El Cultural (versión digital) de Boxeo para células y planetas, montado en la Casa de América en junio de 2006, el autor del artículo, que realiza un balance del trabajo de la dramaturga antes de esta fecha, asume, por su parte, hablar de un estilo grotesco en Angélica Liddell, estilo al que añade la dimensión gótica (volveremos a ello): «Después de varias tentativas en las que abordaba, siempre con ese estilo grotesco y gótico que el espectador recibe como un punch lírico contra sus tripas, problemáticas sociales como la inmigración $-Y$ los peces salieron a combatir contra los hombres-o la matanza de niños en las guerras -Y cómo no se pudrió... Blancanieves - Liddell se zambulle de nuevo en la individualidad $»^{2}$. Por su parte, en fin, José Ramón Fernández, en un artículo del año 2000 sobre La falsa suicida, coloca lo grotesco del lado de la fábula: «Su historia sórdida y casi grotesca se mueve entre bandazos de rock y delicados parpadeos prerrafaelitas. Su eclecticismo es una declaración de libertad absoluta» (Fernández, 2000: 25). Escogía la prudencia al utilizar la fórmula «casi grotesca», que por sí sola dice lo indócil que es la producción de Angélica Liddell a la hora de categorizarla bajo la etiqueta «grotesco».

$\mathrm{Al}$ citar estos tres comentarios, ¿qué hemos querido mostrar? Que estamos frente a un teatro fundamentalmente novedoso, que burla las categorías analíticas preexistentes y requiere, por lo tanto, para poder aprenderlo conceptualmente, una nueva definición de las categorías (sin descartar la posibilidad de que tal empresa desemboque en un fracaso y que haga falta contentarse con medir el fracaso de antiguas herramientas).

Partiremos, pues, para nuestro estudio, de la categoría de lo grotesco e intentaremos confrontar sus características a la escritura, a la puesta en escena y al juego de algunas piezas de Angélica Liddell (utilizo aquí la palabra «pieza» en su sentido etimológico de trocito de un todo ${ }^{3}$ formado por el conjun-

${ }^{2}$ Artículo en línea, sin autor, URL: http://www.elcultural.es/version_papel/LETRAS/17990/Angelica Liddell, publicado el 22 de junio de 2006, consultado el 29 de julio de 2011.

${ }^{3}$ Reproducimos las palabras de Patrice Pavis en su Dictionnaire du théâtre: «En el siglo XVII, una pieza es una obra literaria o musical. La palabra pasa a designar luego exclusivamente el texto dramático, obra escrita para el escenario. De su etimología, la pieza guarda la connotación de un discurso preexistente, puesto en forma, textualizado y remendado, de un ensamblaje artesanal (montaje o collage) de diálogos o de monólogos, lo que le hacía decir a Brecht que su actividad dramatúrgica era la de un "escritor de piezas", de un "Stückeschreiber". Para insistir en el carácter construido y hablado, dirigido directamente al público de sus "obras", Peter Handke habla de "Sprechstücke" o "piezas habladas". Al término "pieza" se le prefiere la noción de "texto" o de "montaje" dramático. Hoy en día los autores ya no reivindican, excepto en la tradición propia del teatro de "Bulevar", que escriben piezas: hablan de "texto", de "montaje", de "reescritura", hasta de "poema dramático"; la organicidad y la regularidad de una pieza a lo antiguo les disgusta». 
to de sus espectáculos, trátese de teatro, performance, acción o demás denominaciones).

Nos apoyaremos para ello en los trabajos que se propusieron desarrollar una teoría de lo grotesco, en su doble dimensión trágica y festiva ${ }^{4}$, analizada por los trabajos magistrales, antinómicos - y ahora tradicionales- de Wolfgang Kayser (1964) y Mijaíl Bajtín (1990). Y más precisamente aún, tomaremos prestado, para nuestro punto de partida, la enérgica síntesis de Véronique Klauber sobre su percepción del concepto desde Francia:

Lo grotesco divide la humanidad en dos campos: al primero pertenecen los que quieren domesticarlo y lo aproximan al efecto de contraste provocado por dos sentimientos o dos categorías estéticas opuestas; para suavizarlo, lo disuelven en un empleo adjetival de la palabra. Lo aproximan, por ejemplo, de lo fantástico y de E. T. A. Hoffman, citan a Bajtín con fervor para asimilar lo grotesco a lo carnavalesco, lo amalgaman con el absurdo a propósito de Wolfgang Kayser, lo confunden con lo burlesco y piensan en Jarry, o del mismo modo se vuelven, hacia Gadda que, gracias a la mezcla barroca de los dialectos y a la expresividad «macarrónica», podría acceder a lo grotesco. [...]

[E]l otro campo [piensa] que lo grotesco francés lo representan un irlandés, un rumano y un belga, y considera natural que un judio de Praga, un polaco o un húngaro no sólo utilicen un estilo, un contenido o una lengua grotesca, sino que escriban el grotesco. Beckett, Ionesco, Michaux, Kafka, Stawomir Mro ek, o István Örkény tienen en común el hecho de que no piensan vencer la realidad, sino que intentan restituirla como el hogar de los seres inverosímiles - es decir, de cualquiera - que, a pesar de la clara conciencia de la nada, luchan para afirmarse (Klauber, 2007).

Partiendo de esta base y para intentar acercar nuestro objeto de estudio, nos preguntaremos si al teatro de Angélica Liddell se le puede asociar el adjetivo «grotesco», si la dramaturga se funde en un efecto de contraste, si pone en práctica categorías estéticas opuestas, o sea, si, a través de este teatro, podemos ponernos del lado del primer campo mencionado por Véronique Klauber. En una segunda etapa, consideraremos, llegado el caso, la hipótesis de un cambio de campo...

${ }^{4}$ Remito aquí especialmente a la síntesis propuesta por García Pascual (2006: 15-74). Guiarán también particularmente nuestra reflexión las actas de dos jornadas de estudio que reunieron a investigadores de varios campos científicos en cuanto a la problemática de lo grotesco (Ost et alii, 2004). 
Desde el punto de vista de la estética, las obras de Angélica Liddell pueden calificarse de neobarrocas, en el sentido de que presentan una exuberancia, un desbordamiento de vida manifiesta a través de los actos, las palabras o los objetos escénicos manipulados. La dramaturgia, rica en invención, deja un espacio importante a la imaginación, a los contrastes, a la transgresión. Se opone en efecto radicalmente a cualquier forma de ideal clásico basado en la búsqueda del equilibrio y de la armonía. Lo que la caracteriza antes que nada es su carácter múltiple, fragmentado, fraccionado, parcelado. En sus espectáculos subyace con fuerza el pulso de una época pasada: la del Barroco, cuando la noción de grotesco estaba «acuñada por un doble sello, el de lo espantoso y el de un cierto cómico, "terribilità" y "cappricio" que Chastel califica de "doble pulsación" de aquella época» (Wellnitz, 2004: 16). Una época que comparte con la de la dramaturga actual el replanteamiento de los valores tradicionales, la conciencia de un cambio necesario y de la dificultad que implica tal mutación, con su cuantía de dolor y de inquietud.

Del lado de lo «terrible» se sitúan, en particular, todas las secuencias en las que la dramaturga-actriz invita a la violencia, directa o indirecta: las escarificaciones, por supuesto (Yo no soy bonita, Te haré invencible con mi derrota, La casa de la fuerza, San Jerónimo...), y todos los ademanes agresivos dirigidos hacia sí misma (un casco de botella de cerveza, la cacerola con leche hirviendo en Yo no soy bonita, el cuerpo emparedado en San Jerónimo), en este proceso de «violencia poética» reivindicada como única arma artística posible para combatir el sufrimiento real:

La violencia poética es necesaria para que lo violento se revuelva contra los depredadores de violencia televisiva y los depredadores de información. Es necesaria para que lo violento se revuelva contra los violentos. (...) Está claro que la violencia poética es lo que se opone a la violencia real (...), de tal modo que el sufrimiento estético y poético acaba convirtiéndose en el sufrimiento real porque es el que verdaderamente nos afecta (Liddell, 2003: $106 \mathrm{y}$ 108).

Dividido entre «el reconocimiento catártico del yo del otro» y la denegación inherente al teatro mismo, el espectador se encuentra situado ante «el esqueleto de un sistema de relaciones humanas caníbal y cruel» (Nut, 2001: $\mathrm{s} / \mathrm{p}$ ). Un esqueleto de aspecto gótico, considerado a la vez en un primer y en un segundo grado.

Y es que los espectáculos de Angélica Liddell están lejos de carecer de humorismo. Si nos situamos en el «capricho», la dramaturga también sabe 
hacer de bufón, y manipular toda una serie de recursos cómicos, entre los cuales el más evidente es el de la repetición, como lo señala, por ejemplo, René Solis a propósito de Maldito sea el hombre que confía en el hombre: un projet d'alphabétisation:

A la vez figura del monstruo, reencarnación a veces del asqueroso que proyectaba en El año de Ricardo, su espectáculo inspirado en el Ricardo III, y penitente consoladora del dolor del mundo, guarda de los niños muertos, Angélica es también el bufón imprecador, aficionado a los soliloquios a la manera de Thomas Bernhard: "Sólo un hombre bueno podría tocar a Schubert. Ni siquiera Schubert podría tocar a Schubert. Los pianos están tan fatigados por nuestra inmundicia que no podemos tocar a Schubert sin ensuciarlo» (Solis, 2011).

La complicidad con la sala, la dramaturga la construye muchas veces mediante el humor, elemento que produce un efecto de distanciación, recordando así su conciencia del juego, rompiendo la ilusión al borrar al personaje en beneficio de la actriz. Pero cuando funciona la máquina escénica, algunos momentos de ruptura cómica irrumpen a contratiempo, generados por un público en fase de denegación mientras que la dramaturga construye para él un «efecto de realidad» del dominio de lo terrible, como lo muestran algunas grabaciones en vídeo 5 . Todos los momentos de oscilación entre lo grave y lo leve remiten sin duda a una estética neobarroca. Óscar Cornago ve incluso en estas tensiones entre contrarios uno de los resortes de la dramaturgia de la artista:

Sus obras están estructuradas sobre un sistema de tensiones entre polos contrarios, una dialéctica no resoluble entre lo espiritual y lo corporal, la pureza y la escatología, lo sublime y lo grotesco, la belleza y el dolor, la inocencia y la culpabilidad, la abstracción conceptual y la concreción material, unión de contrarios que define lo aberrante, lo monstruoso o lo inhumano, obsesiones constantes de su mundo (Cornago, 2005: s/p).

En Angélica Liddell, el ensamblaje «monstruoso», y por lo tanto grotesco, de los opuestos es en efecto una constante en los dominios de la escenografía, de la música, del lenguaje, del juego, etc. Victor Hugo y su Prefacio de Cromwell no están lejos cuando reivindicaban para el drama moderno de

${ }^{5}$ Por ejemplo en la grabación de Perro muerto en tintorería: los fuertes, realizada el 13 de diciembre 2007 en el Teatro Valle-Inclán, sala Francisco Nieva, para el Centro de Documentación Teatral (disponible en su catálogo videográfico). Por ejemplo en los minutos 8'25", 10'55", 14'31', 56'12”, 62'46", 63'11', 63'44", etc. 
su época una mezcla de lo sublime y de lo grotesco, en nombre de cierto realismo, como sabemos. En casi todos los espectáculos, es la música, y particularmente la música barroca, la que crea de la manera más manifiesta un contraste muy fuerte entre «lo sublime» y «lo grotesco», a la manera romántica, diremos. Perro muerto en tintorería convoca el clavecín de Jean-Philippe Rameau, para una pieza escuchada íntegramente:

EL PERRO.-Ahora vamos a escuchar la pieza para clavecín del Concierto primero de mi tío Jean-Philippe Rameau «La Livri». Su duración es de dos minutos. La escucharemos completa y en silencio, Combeferre y yo. (...) Ahora vamos a escuchar con atención la música de mi tío, Jean-Philippe Rameau. Son dos minutos. Y, como dijo Beckett, el ano es el final de la boca, y también dijo, el que pueda entender que entienda.

(Suena Rameau.) (Liddell, 2007: 39).

El efecto de contraste está garantizado: el personaje de El perro, vestido de manera kitch (camiseta de fútbol con la marca de cerveza Carlsberg sobre un vestido corto con enaguas blancas), lleva una carabina y viene a gritar su monólogo de «puto actor» (escena 1), cuando invita al público a que escuche de manera casi religiosa los potentes acuerdos barrocos de La Livri. Una tensión se crea de la misma forma durante la escena de escarificación de Yo no soy bonita, realizada mientras se escucha (a través de un altavoz exterior, en la intimidad del casco que lleva la actriz o mediante la melodía que susurra por encima) de la pieza de Bach La pasión según San Juan. Lo sublime y la sangre de la automutilación mezclados: una fórmula repetida en varias performances: Anfaegtelse ${ }^{6}$, sobre el Andante del Concierto italiano de Bach; San Jerónimo, sobre una música de Bach interpretada en vivo por un violín, esta vez. Al suavizar la imagen de las heridas, la música barroca decupla y magnifica el dolor. En El matrimonio Palavrakis, el infanticidio perpetrado sobre una niña es relatado acompañado de toda una serie de músicas barrocas (Handel, Purcell, Vivaldi y Bach) que intensifican los símbolos trágicos que jalonan la obra y crean un terrible espacio de tensión entre lo monstruoso y lo sublime. De un lado, la dramaturga afirma de la música: «la utilizo de una manera muy primitiva, para entrar en otro estado emocional que me permita llegar hasta donde yo deseo, hasta algún límite que busco en ese momento» (Leguina, 2001: s/p). Por su parte, el público la recibe como un bálsamo, «porque sin ella, quizás no hubiésemos podido sobrevivir al naufragio del alma» (Bély, 2011: s/p).

${ }^{6}$ La tercera parte de su estudio sobre «Temor y Temblor» de Kierkegaard, se titula precisamente Bach en alemán significa río. 
Bach está igualmente presente en La Casa de la fuerza, junto a Vivaldi, para acompañar la violencia padecida por las mujeres mexicanas asesinadas en la frontera norte, por todas las mujeres violentadas; y en Le jour que je suis tombée amoureuse de la voix de Pascal Rambert, está inscrito en el diálogo mismo:

Le jour que je suis tombée amoureuse de la voix de Pascal Rambert, grabé su voz al mismo tiempo que la voz de Alfred Deller,

Alfred Deller cantaba $O$ solitude de Purcell

y Pascal hablaba de la crítica teatral en Francia.

Las dos voces eran parecidas.

[...]

Escuché la voz de Pascal Rambert.

$Y$ empecé a amar el teatro.

Cuando dice «l'espace».

Es el momento que prefiero.

$Y$ cuando dice «bla bla»

Me da un vuelco el corazón y pienso: amo el teatro.

Cuando Pascal dice «bla Bla».

Después grabé la voz de Pascal con Bach

Y luego grabé la voz de Pascal con Schubert.

$Y$ también quedó muy bonito.

$Y$ también amé el teatro.

Y también escuché las grabaciones muchas veces.

En los aviones, en los trenes, en el coche.

Para amar más veces el teatro.

20 años de repugnancia.

Frente a una semana de amor (Liddell, 2011: s/p).

La fórmula final, que aproxima la repugnancia y el amor, es paradigmática de las oposiciones violentas incorporadas por la música, especies de oximorones barrocos, que le hacen escribir a Angélica Liddell: «Son innumerables los genocidas que disfrutan con Schubert» (Liddell, 2003: 108), y a Óscar Cornago: «Desde un enfoque estético amplio, su obra se encuadra dentro del barroquismo que ha caracterizado la Modernidad última» (2011: s/p). Los cánones estéticos de la Postmodernidad son convocados aquí sin duda, mezclados sin embargo de cierto romanticismo, que nos lleva inevitablemente al grotesco de Wolfgang Kayser y a la «paradoja sensible» de Dü- 
rrenmatt (cit. en Kayser, 1964: 9). No es de extrañar, pues, que Angélica Liddell declare: «Me incorporo a la reflexión de Musset, «hay un predominio del sufrimiento en lo moderno» (Liddell, 2003: 106), confirmando con ello su sensibilidad romántica, marcada particularmente a través de su elección de compositores tales como Schubert o Edward Elgar. En Te haré invencible con mi derrota, se escarifica al sonido del Concierto para violonchelo de Elgar; en Maldito sea el hombre que confía en el hombre: un projet d'alphabétisation, es el piano majestuoso de Schubert el que se escucha hasta la náusea.

Nos hemos acercado a los contrastes de la música barroca y romántica con las palabras y los actos violentos desarrollados en el escenario, para mostrar que, en efecto, el teatro de Angélica Liddell está construido en muchos lugares sobre la base de un principio de acercamiento de contrarios. Tal procedimiento se extiende a numerosos dominios, incluyendo al mismo campo musical. De hecho, los «grandes compositores» comparten el escenario con músicas contemporáneas, sea de tendencia rock, pop o flamenco, siempre en esta búsqueda de una tensión máxima entre los opuestos ${ }^{7}$.

La pintura barroca también está convocada para producir un efecto similar. Pensamos en particular en el cuadro de Fragonard El columpio, presente en la escenografía de Perro puerto en tintorería en unas dimensiones que cubren la casi totalidad de la pared izquierda del escenario, y delante del cual se realiza la tercera de las cinco «demostraciones»: «3. Violación. El cuadro de Fragonard acaba en violación. Vamos a terminar el cuadro de Fragonard con una violación». Un simulacro de violación (vestido levantado, bragas bajadas y piernas abiertas frente al público) se mima al pie del cuadro rococó, como si la inocencia y la frescura fueran indisociables de su destrucción violenta; como si sólo el acto violento pudiera demostrarle al hombre pacífico el contrato social que sigue existiendo.

Semejantes tensiones se observan también entre unas manifestaciones de lo sagrado (de la que participa en gran parte la música culta); son, en particular, toda una vena crística que recorre la escenografía ${ }^{8}$, y unas referencias profanas, que van desde lo trivial hasta lo vulgar, y confirman que la escena

${ }^{7}$ Citaremos el caso de la música escogida para los aplausos y la salida del escenario final de $L a$ casa de la fuerza, cuya tonalidad hiperfestiva contrastaba de forma abrupta con la inmensa sensibilidad desarrollada durante las cinco horas del espectáculo y con el estado de exaltación emotiva de los espectadores. Un estudio del cierre de los espectáculos en Angélica Liddell mostraría sin duda que éste sigue formando parte plenamente de la dramaturgia misma.

${ }^{8}$ El ejemplo más evidente es sin duda la puesta en escena de $Y$ los peces salieron a combatir contra los hombres. Un estudio hermenéutico de esta obra mostraría claramente que la temática de la muerte de los emigrantes se traduce en una estética escénica del martirio de Cristo. 
liddeliana está muy impregnada de este «espíritu de lo grotesco» que Patrice Pavis (que nos proporcionó el título del presente estudio) ${ }^{9}$ aproxima al caos, ya que: «[e]n el mundo actual, conocido por su deformidad —es decir, su falta de identidad y de armonía-, lo grotesco renuncia a reflejar una imagen armoniosa de la sociedad: reproduce «miméticamente» su caos, dándonos de él una imagen rediseñada» (Pavis, 2009: 154).

Desde el punto de vista de la estética, el espíritu de lo grotesco se sitúa del mismo modo en la manera con la que la artista enmaraña las fronteras genéricas de sus espectáculos. ¿Teatro, teatro-performance, performance, acción, happening? La insistencia sobre la presencia física de la actriz principal, la misma Angélica Liddell, la elección de un discurso dramático centrado en su propia historia personal, hace de ella una especie de «autobiógrafa escénica que posee una relación directa con los objetos y con la situación de enunciación» (Pavis, op. cit. pág. 246) ${ }^{10}$, e inscribe profundamente su trabajo en la hibridación, «con más atención para con la vitalidad del espectáculo que para con la corrección de la definición teórica de lo que está haciendo» (Pavis, 2009: 246).

Esa es también la conclusión a la que llega Isabelle Ost:

Cultivando la contradicción y la paradoja, el grotesco podría percibirse, en último análisis, como una «anti-estética»; o, por lo menos, un discurso que, porque parece convocar la interpretación y la genericidad, requerir de una definición, y a la vez rechazarlas absolutamente, pone en crisis la organización y las categorías del campo artístico, y hasta la posibilidad misma de una teoría estética (2004: 11).

\footnotetext{
${ }^{9}$ Sin duda, Pavis toma prestada la expresión al crítico y poeta dramático alemán Gerstenberg (cit. en Kayser, 1964: 45), el cual la utiliza en sus Cartas sobre la literatura a propósito de Shakespeare, y quien, en su juicio, escribe: «Lo tiene todo, el espíritu rebosante de imágenes de la naturaleza en descanso y de la naturaleza en movimiento, el espíritu lírico de la ópera, el espíritu de la situación cómica e incluso el espíritu del grotesco, y lo más sorprendente de todo es que nadie puede decir: tiene más de ese espíritu y menos de aquél».

${ }^{10}$ No me resisto a seguir citando a Pavis en relación con el teatro autobiográfico: «El actor autobiográfico no es sólamente un «corazón desnudado», también es un arreglista, un embellecedor, un mostrador y un exhibicionista que trabaja su materia como un escultor trabaja el barro o el escritor las palabras. Y cuando empieza a contar(se), toma sus distancias respecto a su yo presente y se pone en escena en la vida cotidiana (como decía Goffman, 1959). Paradójicamente, el hecho de tener en el escenario a la verdadera persona del actor transforma el proceso de autobiografía, de denudación, en algo sospechoso y artificial, o por lo menos inverosímil: el espectador se pregunta con él: ¿quién soy? ¿Cómo llegué a ser yo? ¿Qué pretendo? El desnudamiento y la autocrítica pública siempre son sospechosos y representados, tanto más cuanto que el actor repite cada noche su confesión, sin modificarla mucho: de ahí la ironía de los confesados: «Les rogué que vinieran todos aquí esta noche para mirarme dármelas de persona interesante» (Pierre Desproges se donne en spectacle, 1986)» (2009: 361-362).
} 
EL «ESPÍRITU DE LO GROTESCO» EN EL TEATRO DE ANGÉLICA LIDDELL

Por lo tanto, no afirmaremos que el teatro de Angélica Liddell pertenece a una estética grotesca, sino más bien que participa del espíritu grotesco tal y como habla de él Pavis.

$$
\text { **** }
$$

Una vez establecida esta constatación, se nos plantea igualmente el problema de posibles elementos utilizados por la dramaturga en sus espectáculos, los cuales podrían identificarse, a pesar de todo, a «figuras grotescas». Efectivamente, además de su carácter paradójico, que ya abordamos anteriormente, algunos «ingredientes» de la dramaturgia liddeliana están estrechamente unidos a la «fuerza de la desfiguración» ${ }^{11}$ que caracteriza de forma particular lo grotesco. Abordaremos aquí, por tanto, tres de dichos ingredientes, que nos parecen de vital importancia: el espacio, el cuerpo y el lenguaje verbal.

El tratamiento del espacio y, en particular, su negación, es, sin duda, un dato fundamental en la definición de lo grotesco ya desde los primeros teóricos, como lo recuerda Isabelle Ost:

En su obra titulada La grottesque, el francés André Chastel enuncia la primera ley del estilo como un gesto de «negación del espacio». Negación, por lo menos, de un espacio muy caracterizado, el espacio cartesiano [...] regido por las normas de la perspectiva. Ahora bien, lo grotesco, que crea, afirma Chastel, «un mundo vertical definido totalmente por el juego gráfico, sin densidad ni peso», produce»un sentimiento de liberación respecto a la extensión concreta en la que reina la gravedad». Uno de los dos rasgos esenciales en las figuras grotescas aparece pues, tras el Renacimiento, como una transformación de la espacialidad, la cual hace que reine la ligereza en lugar de la gravedad, la verticalidad en lugar de las líneas de fuga de la horizontalidad. Rompiendo la perspectiva de fuga unificada alrededor de un punto de vista exclusivo, lo grotesco rechaza el centro y privilegia la verticalidad (Ost, 2004: 29-30).

Tal verticalidad del espacio se observa de forma particular en los espectáculos de Angélica Liddell, que se liberan de todo carácter mimético respecto a una realidad identificable y señalada. El espacio escénico está fragmentado, recortado a la vez por la disposición de objetos dispersos (con frecuencia ritualizados), por zonas dibujadas mediante la utilización de la luz y por la forma en la que los actores hacen y deshacen el espacio lúdico en

${ }^{11}$ Ost (2004: 10) propone esta expresión, que toma prestada del libro de Grossman (2004). 
función del ritmo del espectáculo. Todo ello responde a lo que Stéphane Lojkine define como una «composición performativa», en la que se realiza un ritual.

Por performance entendemos aquí ampliar la noción estrictamente lingüística de palabra performativa al conjunto del ritual en el que esta palabra se inscribe: al o a los protagonistas de la imagen, o de la secuencia textual, se les pone en situación de celebrar un ritual social o religioso, o de participar en él. A partir de ese momento, la performance ya no se define principalmente por tal o cual palabra sacramental (...), sino por el espacio en el que se celebra el ritual (Lojkine, 2011: s/p).

Un espacio que, en Angélica Liddell, es de orden simbólico, o, por seguir utilizando los conceptos de Stéphane Lojkine, de orden «sintáctico», y genera en el espectador el deseo de comprender los sistemas de relaciones propuestas por el espectáculo ${ }^{12}$. Un espacio (des)ordenado de tal forma que pueda acoger «la desnudez sacrificial del actor (en Grotowski o en Brook) ante un espectador que expone así sus preocupaciones y lo más recóndito de su alma a la vista de todos con la esperanza confesa de una redención colectiva» (Pavis, 2009: 306).

Para convencerse de ello, basta con mirar la puesta en escena de $Y$ los peces salieron a combatir contra los hombres, en la que la verticalidad se impone bajo la forma de una gran cruz al fondo del escenario formada por un conjunto de lavadoras; por una suntuosa lámpara de araña colgada del techo y que llega casi hasta el suelo del escenario, que hace pensar en un botafumeiro, amarrada a veces por una enorme soga; por el cuerpo de Sindo Puche colgado por los pies como un San Pedro crucificado boca abajo; por el largo vestido del personaje de La Puta, realizado en un tejido con los colores de la bandera española; por las numerosa botellas de plástico llenas de agua que rodean al personaje central y que remiten al agua en la que mueren ahogados los candidatos a la emigración... La escenografía de Perro muerto en tintorería incorpora, a un lado del escenario, ya lo vimos, una reproducción gigante del cuadro de Fragonard, y al otro, una cascada de hortensias ante la que encontramos un columpio colgado del techo frente a un maniquí realizado por Enrique Marty, colgado en el aire y en posición de descuartiza-

${ }^{12}$ Lojkine afirma: «Es [...] posible caracterizar formalmente una composición performativa con que nos acordemos de que tal caracterización no será de orden geometral, como en una escena, sino más bien de orden simbólico o sintáctico. Lo cual no se traduce visualmente de la misma manera: lo que pasa a ser primordial, es el análisis de un sistema de relaciones» (art. cit.). Ver al respecto Garnier (2011c). 
miento. Al fondo del escenario vemos una cuerda con un nudo corredizo que la actriz trata de coger hacia el final de la obra. El columpio reaparece en $E l$ matrimonio Palavrakis, obra en la que la horizontalidad del suelo se ve sustituida por una montaña de cuerpos de muñecas de plástico con los miembros desarticulados, en la que unos globos cuelgan sobre juguetes mecánicos y donde los personajes se iluminan a veces el rostro con una linterna colocada bajo la barbilla, ofreciendo así una imagen alargada verticalmente. En Once upon a time in West Asphixia el techo está tapizado con osos de peluche colgados como en una barraca de feria. En Histerica Passio, numerosos hilos rojos unen a los personajes en escena a unas guirnaldas de luces de feria... La lista sería prolija en exceso si enumeráramos todos los procedimientos escénicos que se utilizan y que fuerzan hacia un desequilibrio vertical (por ejemplo todos los recursos a proyecciones en pantallas colocadas a una cierta altura), y borran, por ello, casi totalmente el eje horizontal, rompiendo así, por consiguiente, «con un principio espacial esencial, el de la simetría» - tal y como recuerda Ost en su estudio sobre lo grotesco en relación al espacio (2004: 32) - y por lo tanto con el principio del equilibrio.

Una ruptura idéntica con la armonía se produce en cuanto al cuerpo en el teatro de Angélica Liddell. Un cuerpo con frecuencia deformado, monstruoso, maltratado, y en ocasiones protegido y mimado.

A propósito de Frankenstein, una de sus primeras obras, Angélica Liddell explicaba ya su posición sobre lo monstruoso: «Nos ponemos a favor del monstruo y pretendemos que todo el mundo se ponga a favor del que sufre», y, siguiendo en una lógica totalmente esperpéntica, justificaba la elección de personajes-marionetas por el hecho de que «en esta obra aportan más credibilidad que los actores» (cit. en Muñoz-Rojas, 1998: s/p). Posteriormente, serán los maniquíes de Enrique Marty los que aparecerán en el escenario para mezclarse con los cuerpos de carne y hueso, sobre todo en Perro muerto en tintorería, en donde algunos son los moldes de resina de los actores desnudos. Más tarde, en Maldito sea el hombre que confía en el hombre: un projet d'alphabétisation, la escultura final opera como doble doliente de los atletas chinos que aparecen antes en escena, como si se tratase de una última perspectiva trágica.

Estos cuerpos humanos de resina, pueden estar también deformados por su talla. Es incontable el número de muñecas utilizadas en los diferentes espectáculos de la artista: en El matrimonio Palavrakis y en las otras dos obras de la trilogía del Tríptico de la aflicción, en particular. Sin contar las proyecciones de imágenes en escena que introducen casi au- 
tomáticamente un cambio de escala en relación a los cuerpos que aparecen en el espacio escénico.

La presencia de dichos objetos de tipo corporal hace que aflore una dialéctica barroca que recorre toda la obra de Angélica Liddell: la de la vida y la muerte. Las muñecas manipuladas por los actores como hacen los niños, pero en un juego muchas veces perverso (recordemos aquí la mancha de sangre en el vestido de la muñeca/Chloé sugiriendo la violación por parte del padre en El matrimonio Palavrakis), reflejan un mundo mórbido, al igual que los maniquíes amontonados en el sofá de Perro muerto en tintorería cuando se trata de crear un cuadro vivo (en caso de que pueda calificarse de ese modo) de Europa: una alternancia de cuerpos vivos e inertes. Presenciamos aquí uno de los fundamentos de lo grotesco: la representación de lo humano deshumanizado. Un cuerpo que en una perspectiva semiológica es un signo teatral fundamental y cuya deformación, tal y como lo formula Christilla Vasserot «puede de este modo beneficiarse de una doble interpretación: es el signo de una individualidad exacerbada o bien de una deformación de la norma social (del cuerpo social al que remite el cuerpo individual» (2002: 7). En Angélica Liddell esta doble orientación es constante.

El procedimiento que permite que tome cuerpo la dialéctica vida-muerte, se activa también con la utilización reiterativa de animales disecados en el escenario. El jabalí de El año de Ricardo, los conejos de Maldito sea el hombre que confía en el hombre: un projet d'alphabétisation o Yo no soy bonita, encarnan a la perfección la monstruosidad de cuerpos desnaturalizados, formarían parte de lo grotesco trágico si los actores/personajes no interactuasen a veces con ellos en un registro puramente lúdico y, en ocasiones, con gran dulzura.

Paralelamente a su deformación, el cuerpo muestra sus partes «bajas» a semejanza del cuerpo grotesco del carnaval medieval. En este sentido, algo del realismo grotesco definido por Bajtín funciona en el teatro de Angélica Liddell. La verticalidad observada en el empleo del espacio se encuentra aquí completada por una tendencia a la disminución: «El rasgo fundamental del realismo grotesco es la disminución, es decir el transfert de todo lo que es elevado, espiritual, ideal y abstracto en el plano material y corporal, el de la tierra y el cuerpo en su indisoluble unidad» (Bakhtine, 1990: 29).

De tal forma que son numerosos los espectáculos en los que el cuerpo se muestra desnudo o en los que el juego de los actores implica el desnudo de las partes íntimas del cuerpo: sexo, nalgas, senos... La obra más ilustrativa de tal exhibición es, sin duda, El año de Ricardo, en la que el juego com- 
pulsivo del personaje de Ricardo, enfermo y en pleno delirio, casi demoníaco, lleva a la actriz a ponerse en cuclillas de manera regular bajando el pantalón de su pijama con un propósito escatológico evidente, a la vez que comenta (e igualmente mima) sus diarreas y vómitos, escalofríos o vértigos que ni siquiera el litio que ingiere Ricardo regularmente consigue detener.

El sexo exhibido, masculino o femenino, ocupa un lugar importante en la dramaturgia de Angélica Liddell. Un sexo a veces trivial, a veces provocador, y cuyo desvelamiento o exposición adquiere un gran número de sentidos posibles: la violencia, el alumbramiento, la sexualidad, el placer, la realidad corporal del ser, la impotencia, la indigencia, la fragilidad...

En Yo no soy bonita, el cuerpo es a la vez «rebajado» y deformado cuando la actriz muestra y comenta un cartel que representa la foto de una felación en primer plano. Por su color, sus formas y sobre todo su talla proporcional al espacio escénico, el pene en erección, acompañado de una rubia estereotipada de labios carnosos (otra forma de muñeca), sitúa al espectador a medio camino entre la tristeza y la risa falsa, entre lo patético y la ironía; en una palabra, lo sumerge en una forma de grotesco romántico en el que, según Bajtín: «la risa ha disminuido, adquiere forma del humor, de la ironía, del sarcasmo. Deja de ser alegre y feliz. El aspecto regenerador y positivo de la risa se ha reducido al mínimo» (Bakhtine, 1990: 47).

El sexo masculino aparece a menudo desnudo, ya sea de forma puntual, con efectos (y sin duda intenciones) diversos: ya sea de manera triunfante, festiva o lúdica, o bien de forma agresiva, compasiva y siniestra, y muy frecuentemente sin que sea fácil determinar de forma evidente el registro utilizado. En $Y$ los peces salieron a combatir contra los hombres, la desnudez del actor es ante todo una referencia directa a la plástica cristiana del sufrimiento y de la compasión. En El matrimonio Palavrakis, el actor embadurna su sexo con el pastel de cumpleaños de su hijita Chloé muerta, de la que ha abusado durante toda su vida. El texto de la obra escribe, en la didascalia final, y en mayúsculas:

ALELUYA. EL MESÍAS DE HAENDEL. DE UN MODO ENSORDECEDOR. MATEO PALAVRAKIS SE EMBADURNA EL SEXO CON LA TARTA DE CUMPLEAÑOS. ELSA PALAVRAKIS FOTOGRAFÍA AL SEÑOR PALAVRAKIS Y LANZA LAS FOTOS AL PÚBLICO.

La desnudez final construye así un clímax a la vez orgiástico y abyecto, totalmente paradigmático de la manera en la que Angélica Liddell trabaja la cuestión de lo monstruoso. 
De igual modo, el sexo femenino puede ser desviado de todo voyeurismo o por el contrario jugar con él. Siguiendo con El matrimonio Palavrakis, el personaje de Mateo, el marido, empieza a hablarle a su futuro hijo dirigiéndose a la vagina de su mujer en una postura escénica próxima al Origen del mundo, pero en calzoncillos de seda de color perla. En Perro muerto en tintorería, la violación bajo El columpio de Fragonard se trata mediante la ausencia, en el sentido de que el público «sólo» ve el sexo abierto de la actriz - y no el sexo masculino amenazante- , un sexo femenino percibido con extrema dulzura. Idéntica impresión se desprende de la azotaina de Maldito sea el hombre que confía en el hombre: un projet d'alphabétisation, cuando uno de los personajes femeninos está tumbado sobre las rodillas de otro personaje femenino para recibir un azote que finalmente no se produce porque el gesto escénico se congela en el momento en el que el público espera la palmada y en el que, sin duda, él mismo la reproduce mentalmente en el momento en el que el espectáculo lo orienta hacia una lectura inmensamente más delicada.

A esta delicadeza que siempre llega a contratiempo, se opone un tratamiento cruel del cuerpo. Éste aparece de forma directa a través de las escarificaciones y otro tipo de escenas en las que la actriz martiriza su cuerpo con escenas con las que, ya lo hemos visto, la dramaturga entiende así poner en funcionamiento su violencia poética —escenas que, por otra parte, están cercanas a conductas de automutilación asociadas a la cultura gótica con la que a veces se intenta unir el nombre de Angélica Liddell-. Pero la crueldad está presente en su teatro sobre todo a través de los temas tratados y en su lenguaje.

La guerra (Belgrado, El año de Ricardo), la matanza de niños inocentes ( $Y$ como no se pudrió Blancanieves), la masacre de mujeres (La casa de la fuerza), la violación de niñas (El matrimonio Palavrakis), la hecatombe de los emigrantes africanos ( $Y$ los peces salieron a combatir contra los hombres), la enfermedad (Te haré invencible con mi derrota, Boxeo para células $y$ planetas), son varios de los temas tratados con rabia y crueldad. Una crueldad que recuerda sin cesar a la locura, y en la que lo grotesco, ya lo hemos visto, no está del todo ausente.

Porque del mismo modo que el gesto de la crueldad es un «gesto del desvelamiento siempre reiniciado de lo más oscuro, de la revelación de los más secreto», el espíritu grotesco que rodea las obras de Angélica Liddell «lleva a confrontarnos a la sobre humanidad que habita en lo más íntimo del hombre, al exceso, a la desmesura como dimensión constitutiva de la norma y de lo racional». De tal forma que en su teatro: 
Al igual que la crueldad, lo grotesco revela los posibles extremos de una humanidad que se sobrepasa sí misma, en la tensión paradójica de una norma fundada en lo que la transgrede. Ya que lo dionisíaco, fuerza suprema de lo grotesco y de la crueldad, encuentra su fuerza, para Nietzsche, en el anverso de la ley, en el punto crucial de su autodestrucción (Ost, 2004: 35).

De ahí la imagen evocada por la dramaturga en su texto teórico El mono que aprieta los testículos de Pasolini: «El cuerpo enfermo se hace verbo. Mi obra acaba siendo una oveja rabiosa y epiléptica, inevitablemente oveja de la manada, pero al menos oveja rabiosa» (Liddell, 2003: 106).

Crudeza, dulzura y crueldad en el tratamiento escénico del cuerpo, forman, sin duda, una palabra completa, pero ésta se encuentra decuplada por su articulación con el lenguaje verbal, otro ingrediente del teatro liddeliano que participa de la «fuerza de desfiguración» grotesca. La deformación del lenguaje, su utilización monstruosa, siguen la misma lógica que el rebajamiento del cuerpo y la verticalidad del espacio.

En el primer caso, la dramaturga maltrata el lenguaje del mismo modo que martiriza a los cuerpos: cuerpos descritos, órganos nombrados, gestos relatados sin pudor, sin eufemismos. Ahí el texto dramático se abre al registro de lo grosero en línea con la cultura trash, remitiendo la violencia verbal a la violencia de lo real:

$Y$ después me puse a desnudarme en el chat

Me pintaba la boca de rojo,

me ponía unas bragas bonitas,

un sujetador bonito

$Y$ conectaba la web cam

Ellos me enseñaban la polla

Les decía, no me enseñes la cara, hijo de puta, no me enseñes la cara,

Enséñame sólo la polla.

Y yo no les enseñaba la cara

Y les decía que me pidieran cosas

Me pedían que me metiera el dedo en el culo

Y yo lo hacía

Me pedían que me metiera el dedo en el coño

Y yo lo hacía

Me pedían que me pellizcara los pezones 
Y yo lo hacía

Me pedían que me masturbara

Y yo lo hacía

$Y$ me corría de verdad

$Y$ algunos me pedian que me meara encima

Pero yo no podía mear

Yo así como así, no puedo mear.

Y los tíos se asombraban de que yo hiciera todo eso gratis

Eso cuesta dinero, decían, eso cuesta dinero

Por eso se cobra

Dame tu puto Messenger

Cuándo quedamos, tía, cuándo quedamos.

Pues mira, sí

Yo era una puta gratuita

porque entre frase guarra y frase guarra

Ellos decían, cariño, cielo, guapa, preciosa

Y yo me lo creía

Cuando no tienes amor verdadero

Cualquier gilipollez

La experimentas como un sucedáneo del amor. ${ }^{13}$

Además de la utilización de tacos, un lenguaje grosero, temas crudos y obscenos, el lenguaje liddelliano entremezcla con frecuencia diferentes enunciados con largos monólogos desfasados en relación a la actuación o incluso al mismo sexo de los actores (en La casa de la fuerza son las mujeres las que asumen el discurso de los hombres violentos). De este modo deshace la sintaxis, la desgarra:

De tal forma que al flujo lineal y horizontal del discurso se superpone la verticalidad de un texto con réplicas (¿tiradas?) colocadas en sangrías, físicamente despedazadas, colgadas de la única columna vertebral del margen izquierdo, y cuyas repeticiones lancinantes obstaculizan en parte - pero sólo en parte- la recepción de la lógica gramatical y el sentido del discurso (Garnier, 2011b).

\footnotetext{
${ }^{13}$ Angélica Liddell, La casa de la fuerza, texto inédito.
} 
La verticalidad textual se une aquí a la verticalidad escénica y refuerza así la desfiguración grotesca. Ésta se encuentra igualmente intensificada, en la práctica totalidad de la producción de Angélica Liddell, a través de un gran número de reiteraciones de palabras, de segmentos de frases, con o sin variaciones. En un estudio anterior sobre El año de Ricardo, utilizábamos el concepto de «repetición-variación» propuesto por Michel Vinaver:

Estas «repeticiones-variaciones» - tal como las define Michel Vinaver ${ }^{14}$ son el punto de unión que se produce en la material del lenguaje [...] —efectos rítmicos, frotamiento de sonidos, derrapages de sentido de una frase a otra, colisiones que desencadenan como minifenómenos de descargas irónicas» (Vinaver, 1082: 125). En ocasiones parecen cantinelas que «imprimen a la lengua un ritmo, una resonancia que excita al cuerpo» ${ }^{15}$ y, en el contexto de ironía y cinismo de la obra, funcionan como «descargas eléctricas», de tal forma que constatamos, tal y como hace Michel Vinaver al analizar sus propios textos: «De pronto, pasa. ¿Qué pasa? Una corriente de sentido»(Vinaver, 1982: 125).

Una corriente de sentido que alcanza, en todos los casos, la subversión como herramienta de verdad.

Para concluir esta breve reflexión sobre la eventual presencia de una forma de grotesco en el teatro de Angélica Liddell, debemos constatar una cierta similitud entre los contornos de sus producciones y el poder de subversión de lo grotesco, ya que, cada uno a su manera, «se muestra capaz de desmantelar los discursos recibidos, de llevar a escena los entresijos de la creación estética, y de desplazar las fronteras que separan géneros y estilos poniendo de relieve sus principios fundadores implícitos» (Ost, 2004: 10).

¿En qué sentidos(s) desembocan estas figuras de la deformidad presentes en el tratamiento del espacio, del cuerpo y del lenguaje? Porque participan en un «proceso antidialéctico capaz de negar la identidad conceptual para distanciarse de la lógica de la significación», enviaremos estas figuras, tal y como lo hace Isabelle Ost a propósito de lo grotesco, al territorio de la utopía. Y podremos afirmar, igual que para lo grotesco, que la dramaturga es-

${ }^{14}$ Para el dramaturgo francés, una «repetición-variación «es la reiteración de un elemento textual pasado, pero con una diferencia que puede situarse en la forma, o en el sentido, o en los dos» (Vinaver, 2000: 903). (2002).

${ }^{15}$ Sobre el concepto de «cantinela», tomado prestado de Gilles Deleuze y Félix Guattari, ver Fiat 
pañola «descentra, deslocaliza los lugares de poder para inventar una realidad nueva. Situad[a] en un juego entre subversión de las reglas y los cimientos de sus propias leyes, nos invita a una reflexión sobre la normativa en todos los campos de la creatividad — social, política, artística o de cualquier otro tipo-》 (Ost, 2004: 9).

En este sentido, Angélica Liddell pertenece, sin duda alguna, a aquellos que como Beckett, Ionesco, Michaux, Kafka, Mrozek u Örkény, «no imaginan vencer a lo real, sino que intentar referirlo como el hogar de seres inverosímiles - es decir como cada uno - que, a pesar de la clara conciencia de la nada, luchan por afirmarse» (Klauber, 2011).

Dejemos pues a la creadora la última palabra:

En el fondo, el teatro no existe. Existen las aspiraciones artísticas. O deberían existir. El objetivo es el arte. Y hay que cumplir el objetivo con rabia. Debemos cultivar la rabia siempre. Ir en contra. Protestar mientras nos queden valor y fuerzas para sobrevivir sin dinero. Eso significa desterrar la eficacia y la corrección (Liddell, 1992: 43).

\section{REFERENCIAS BIBLIOGRÁFICAS}

BAKHTINE, M. (1990). L'Euvre de François Rabelais et la culture populaire au Moyen Âge et sous la Renaissance. Traducción francesa de Andrée Robel. París: Gallimard.

BÉLY, P. (2011). «Espectador de La Casa de la fuerza en 2010 en Aviñón». Artículo en línea http://www.festivalier.net. Consultado el 30 de julio de 2011.

CHASTEL, A. (1988). La grottesque. París: Le Promeneur.

CORNAGO BERNAL, Ó. (2005). «Atra Bilis o el rito de la perversión». Artículo en línea en http://artesescenicas.uclm.es/index.php? sec =texto\&id $=25 \&$ PHPSESSID $=$ azhwlexmmzvpjcee. . Consultado el 8 de junio de 2011.

FERNÁNDEZ, J. R. (2000) «La falsa suicida, de Angélica Liddell, en La Cuarta Pared». Primer Acto 282, 24-25.

FIAT, Ch. (2002). La ritournelle, une anti-théorie. París: Léo Scheer. 
EL «ESPÍRITU DE LO GROTESCO» EN EL TEATRO DE ANGÉLICA LIDDELL

FRANCISCO, I. de (2004). «Angélica Liddell : "El teatro es un corral lleno de gallinas resentidas"». El Cultural (El Mundo), 01/04. http://www.elcultural.es/version_papel/TEATRO/9234/Angelica_Liddell. Consultado el 29 de julio de 2011.

GARCÍA PASCUAL, R. (2006). Formas e imágenes grotescas en el teatro español contemporáneo. Madrid: Universidad Complutense.

GARNIER, E. (2011a). Le tragique au féminin: les dramaturges femmes dans l'Espagne contemporaine Paris: L'Harmattan.

- (2011b) «El año de Ricardo de Angélica Liddell: de la scène au texte, essai de "logocentrisme à l'envers"». En Le texte dramatique contemporain, Orient/Occident. En I. Reck (ed.). Estrasburgo: Université de Strasbourg (en prensa).

- (2011c). «Rapports de force dans Yo no soy bonita, de Angélica Liddell». En Théâtralité de la scène érotique dans la littérature et dans les arts de l'image et du spectacle de 1970 à nos jours, Jornada de Estudio organizada en la Universidad de Toulouse II por Muriel Plana y Hélène Beauchamp (en prensa).

- (ed.) (2007). Transgression et folie dans les dramaturgies féminines hispaniques contemporaines. Carnières-Moranwelz: Lansman.

GROSSMAN, E. (2004). La défiguration. Artaud-Beckett-Michaux. París: Minuit.

KAYSER, W. (1964). Lo grotesco, su configuración en pintura y literatura. Buenos Aires: Nova.

KLAUBER, V. (2011). «Grotesque, littérature». Encyclopaedia Universalis. Artículo en línea en http://www.universalis-edu.com/encyclopediel grotesque-litterature/\#. Consultado el 29 de julio de 2011.

LEGUINA, Leire (2011). «Angélica Liddell: pornografía del alma». Entrevista en línea en http://revistametal.com/media/i14-7-angelicaliddell.html. Consultado el 30 de julio de 2011.

LIDDELL, A. (1998). «Una reflexión dramatúrgica del presente». Primer Acto 272, 43.

- (2003). «El mono que aprieta los testículos de Pasolini». Primer Acto 300, 104-108.

- (2007). Perro muerto en tintorería: los fuertes. Primer Acto 321. 
- (2011). Le jour que je suis tombée amoureuse de la voix de Pascal Rambert. Texto en línea en http://dramangular.com/textosteatrals/Le jour que je suis tombée amoureuse de la voix de Pascal Rambert.pdf. Consultado el 30 de julio de 2011.

LOJKINE, S. (2011). «Perfomance». Artículo en línea en http://www.univmontp3.fr/pictura/AideRecherche.php? numero $=24$. Consultado el 31 de julio de 2011.

MUÑOZ-ROJAS, R. (1998). «Estreno de un musical y una obra de títeres. Dos montajes sobre Frankenstein ofrecen visiones diferentes del mito». El País 08/01.

NUT, Pau de (2011). «Montaje de Mi relación con la comida». En http://www.nauivanow.com/HTMLTextArea/Mi\%20relaci\%C3\%B3n_1. pdf. Consultado el 30 de julio de 2011.

OST, I.; PIRET, P. y VAN EYNDE, L. (eds.) (2004). Le grotesque, théorie, généalogie, figures. Bruselas: Faculté Universitaire Saint-Louis.

PAVIS, P. (2009). Dictionnaire du théâtre. París: Armand Colin.

SOLIS, R. (2011) «Angélica Liddell, la douleur de A à Z». Libération 11/07. Artículo en línea en http://www.liberation.fr/culture/01012348295angelica-liddell-la-douleur-de-a-a-z. Consultado el 30 de julio de 2011.

VASSEROT, Ch. (2002). «Le théâtre, ce corps à corps». En Le corps grotesque, C. Vasserot (ed.), 5-11. Carnières-Moranwelz: Lansman.

VINAVER, M. (1982). Écrits sur le théâtre. Lausanne: L'Aire.

- (2000). Écritures dramatiques. Essais d'analyse de textes de théâtre. Arles: Actes Sud.

WELLNITZ, P. (2004). «Le grotesque littéraire». En Le grotesque, théorie, généalogie, figures, I. Ost, P. Piret, L. Van Eynde (eds.), 13-25. Bruselas: Faculté Universitaire Saint-Louis. 